\title{
The inpatient colonoscopy: A worthwhile endeavour
}

\author{
Darin Krygier MD FRCPC, Robert Enns MD FRCPC
}

$\mathrm{I}^{\mathrm{n}}$ n the November 2008 issue of The Canadian Journal of Gastroenterology, the difficulties and limitations associated with the performance of colonoscopy in hospitalized patients were discussed. In contrast, the present article will discuss the rationale behind the use of inpatient colonoscopy and present the evidence that supports this practice.

The most evident advantage to the performance of inpatient colonoscopy is clearly its ability to expedite the assessment of patients who would otherwise wait weeks or months to have the procedure performed as an outpatient. The Canadian Association of Gastroenterology has published target wait times (1) that have been deemed acceptable for patients waiting to be assessed by a gastroenterologist, ranging from two weeks for those with suspected malignancy and inflammatory bowel disease, to two months for those with iron deficiency anemia and positive fecal occult blood tests $(1,2)$. Recent studies suggest that total wait times exceed the consensus targets, with $51 \%$ to $88 \%$ of patients not being seen within the target wait time. Given the large backlog of patients waiting to be assessed by most gastroenterologists, it is not surprising that the wait time for outpatient endoscopy often exceeds six to 12 months. As a result, colonoscopy performed while hospitalized can greatly expedite the management of patients with gastrointestinal issues.

Another benefit of inpatient colonoscopy is the ability to perform the procedure in patients who may not otherwise reliably make themselves available for outpatient procedures, often due to socioeconomic or other situational factors. Additionally, it facilitates the preprocedural care of those patients who require such interventions as prophylaxis against bacterial endocarditis and titration of systemic anticoagulation. These patients can often be more difficult to coordinate before outpatient colonoscopy.

\section{INDICATIONS}

The diagnostic yield of colonoscopy is greatly diminished when it is performed for inappropriate indications (3-5). The largest body of evidence supporting the performance of inpatient colonoscopy comes from studies evaluating patients with lower gastrointestinal bleeding (6-11). Some studies have suggested that urgent inpatient colonoscopy in the setting of acute lower gastrointestinal bleeding may lead to higher rates of bleeding source localization, reduced rates of emergency colorectal surgery and shorter lengths of stay in hospital. The evidence, however, is somewhat controversial and at the St Paul's Hospital, Vancouver, British Columbia, not all patients (particularly those with minor lower gastrointestinal bleeding) undergo urgent inpatient colonoscopy. Those with severe lower gastrointestinal bleeding will undergo urgent endoscopic assessment.

Perhaps even more controversy exists regarding the role of inpatient colonoscopy in the evaluation of chronic diarrhea, iron deficiency anemia and positive fecal occult blood tests. To our knowledge, there is little, if any, compelling evidence to support the use of inpatient colonoscopy in their evaluation. Most patients who present with such indications likely could be appropriately dealt with as outpatients. Despite this, there are certain instances in which inpatient assessment is both practical and beneficial. Such situations include patients who live in remote underserviced communities, who are admitted to hospital elsewhere. In this situation, an inpatient colonoscopy could greatly expedite definitive care for those who ultimately require colorectal surgery or other specialized intervention that would not be available to them in their home communities. Given the vast geographic area of Canada and the relative scarcity of trained endoscopists, this is not an uncommon situation.

\section{PREPARATION}

The quality of a patient's bowel preparation has a crucial impact on the diagnostic yield of colonoscopy and the need for repeat procedures (12). This is especially true for small lesions and flat lesions, which are often difficult to detect even under ideal circumstances. Several studies have determined that inpatient status is an independent predictor of poor bowel preparation (13-15). Other factors, such as a reported failure to follow preparation instructions, a procedural indication of constipation, male sex and a history of cirrhosis, stroke or dementia have also been found to independently predict inadequate colon preparation. All of this leads to reduced enthusiasm among endoscopists toward performance of inpatient colonoscopy. Interestingly, a patient's perception about the quality of their bowel preparation is often inaccurate (16). Perhaps the issue of poor inpatient preparation can be partially overcome by

St Paul's Hospital, University of British Columbia, Vancouver, British Columbia

Correspondence: Dr Robert Enns, St Paul's Hospital, University of British Columbia, Pacific Gastroenterology Associates, 770 - 1190 Hornby

Street,Vancouver, British Columbia V6Z 2K5. Telephone 604-688-6332, fax 604-689-2004, e-mail renns@interchange.ubc.ca

Received and accepted for publication October 30, 2008. 
more carefully selecting patients in whom preparation is more likely to be adequate and by the use of more rigorous bowel preparation (ie, two-day preparations). It may also be useful for the nursing staff, who will be administering the bowel preparation, and the patient that will be taking it, to be educated regarding the importance of taking it as prescribed.

Generally speaking, most of the available bowel preparations have been determined to have similar efficacy $(17,18)$. Variability has been found in the tolerability of preparations, making some more likely to be taken as instructed by patients. Some studies (19), for instance, suggest that sodium phosphate preparations are better tolerated than polyethylene glycol. Certain patient factors, such as renal or cardiac dysfunction, should prompt the preferential use of polyethylene glycol for safety reasons. Essentially, whatever preparation chosen by the endoscopist is most effective when taken as directed. This is most likely to occur when patients in hospital understand the reason for the procedure and the preparation. With appropriate education and monitoring of their use, we believe that inhospital preparations can be improved.

\section{POPULATION}

It is true that those patients in hospital being considered for inpatient colonoscopy very often have numerous other medical issues. This can complicate not only the actual performance of the procedure, but also the ability to achieve adequate bowel preparation. Studies have shown that patients with diabetes, chronic renal disease, chronic obstructive pulmonary disease and chronic constipation require more aggressive bowel preparations before colonoscopy to avoid the need for repeated procedures (20). The use of narcotics and laxatives, both of which are commonly required by inpatients, have also been found to predict those patients who require more intensive bowel cleansing regimens to optimize preparation before colonoscopy. This magnifies the importance of selecting patients with appropriate indications who are engaged in their own care. In these patients, inpatient colonoscopy can be performed safely and can provide information that may be used to competently direct their management. Even in patients older than 80 years of age, many of whom have multiple comorbid diseases, colonoscopy has been found to have a high diagnostic yield and a complication rate as low as that for younger patients (21).

\section{REFERENCES}

1. Leddin D, Armstrong D, Barkun AN, et al. Access to specialist gastroenterology care in Canada: Comparison of wait times and consensus targets. Can J Gastroenterol 2008;22:161-7.

2. Yu D, Hopman WM, Paterson WG. Wait time for endoscopic evaluation at a Canadian tertiary care centre: Comparison with Canadian Association of Gastroenterology targets. Can J Gastroenterol 2008;22:621-6.

3. Appropriate use of gastrointestinal endoscopy. American Society for Gastrointestinal Endoscopy. Gastrointest Endosc 2000;52:831-7.

4. Minoli G, Muecci G, Bartoli A, et al. The ASGE guidelines for the appropriate use of colonoscopy in an open access system. Gastrointest Endosc 2000;52:39-44.

5. Siddique I, Mohan K, Hasan F, et al. Appropriateness of indication and diagnostic yield of colonoscopy: First report based on the 2000 guidelines of the American Society for Gastrointestinal Endoscopy. World J Gastroenterol 2005;11:7007-13.

6. Clarke GA, Jacobson BC, Hammett RJ, Carr-Locke DL. The indications, utilization and safety of gastrointestinal endoscopy in an extremely elderly patient cohort. Endoscopy 2001;33:580-4.

7. Jensen DM, Machicado GA, Jutabha R, Kovacs TO. Urgent colonoscopy for the diagnosis and treatment of severe diverticular hemorrhage. N Engl J Med 2000;342:78-82.

\section{TRAINING}

It is beneficial for trainees to gain exposure to these complex patients in a graduated manner so that they can continue to further their endoscopy skills under expert supervision. This will ultimately contribute to the long-term development of competent endoscopists who will continue to serve the public at large. The evidence (22) suggests that endoscopy success rates improve with experience and higher annual procedure volume, particularly in the early years after completion of training. In fact, better results have been associated with a volume of at least 100 to 200 procedures per year. Since most gastroenterology fellows spend the bulk of their training working in a hospital setting, inpatient endoscopy comprises a significant portion of their procedural experience.

\section{SCHEDULING}

Most larger endoscopy units have endoscopy slates prearranged for 'predicted' inpatients to be evaluated. Even if they do not, if one assesses the booking early in the day, there is often room or a possibility of adding a case during a slate that was previously stated to be 'full'. Adding a case in this situation, therefore, improves efficiency because an extra case is being performed often in the same amount of time that had already been booked without requiring increased resources. Therefore, the availability of inpatients to be 'plugged' into the slate has the possibility of improving the use of existing resources, while maximizing available resources, as long as the staff are astute and can fill 'holes' created when outpatients do not attend their scheduled slots by fitting-in an inpatient.

\section{SUMMARY}

Inpatient colonoscopy is safe and can contribute to the expedited management of complex patients. Although many of these patients can theoretically be managed and investigated as outpatients, the Canadian environment of waiting lists often encourages the inpatient colonoscopy. To perform these procedures successfully, patients must have the appropriate indications and adequate bowel preparation. This requires careful and diligent patient selection in addition to a high level of technical competence. Inpatient colonoscopy also offers an opportunity to enhance the skills of training endoscopists in a graded manner under careful expert supervision can lead to expedited diagnosis and management with the potential to improve patient outcomes.

8. Joosten E, Ghesquiere B, Linthoudt H, et al. Upper and lower gastrointestinal evaluation of elderly inpatients who are iron deficient. Am J Med. 1999;107:24-9.

9. Schmulewitz N, Fisher DA, Rockey DC. Early colonoscopy for acute lower GI bleeding predicts shorter hospital stay: A retrospective study of experience in a single center. Gastrointest Endosc 2003;58:841-6.

10. Strate LL, Syngal S. Timing of colonoscopy: Impact on length of hospital stay in patients with acute lower intestinal bleeding. Am J Gastroenterol 2003;98:317-22.

11. Green BT, Rockey DC, Portwood G, et al. Urgent colonoscopy for evaluation and management of acute lower gastrointestinal hemorrhage: A randomized controlled trial. Am J Gastroenterol 2005; 100:2395-402.

12. Harewood GC, Sharma VK, de Garmo P. Impact of colonoscopy preparation quality on detection of suspected colonic neoplasia. Gastrointest Endosc 2003;58:76-9.

13. Chorev N, Cahdad B, Segal N, et al. Preparation for colonoscopy in hospitalized patients. Dig Dis Sci 2007;52: 835-9.

14. Ness RM, Manam R, Hoen H, Chalasani N. Predictors of inadequate bowel preparation for colonoscopy. Am J Gastroenterol 2001;96:1797-802. 
15. Hendry PO, Jenkins JT, Diament RH. The impact of poor bowel preparation on colonoscopy: A prospective single centre study of 10,571 colonoscopies. Colorectal Dis 2007;9:745-8.

16. Harewood GC, Wright CA, Baron TH. Assessment of patients' perceptions of bowel preparation quality at colonoscopy. Am J Gastroenterol 2004;99:839-43.

17. Barkun AN, Chiba N, Enns R, et al. Commonly used preparations for colonoscopy: Efficacy, tolerability, and safety - A Canadian Association of Gastroenterology position paper. Can J Gastroenterol 2006;20:699-710

18. Hsu CW, Imperiale TF. Meta-analysis and cost comparison of polyethylene glycol lavage versus sodium phosphate for colonoscopy preparation. Gastrointest Endosc 1998;48:276-82.
19. Young CJ, Simpson RR, King DW, Lubowski DZ. Oral sodium phosphate solution is a superior colonoscopy preparation to polyethylene glycol with bisacodyl. Dis Colon Rectum 2000;43:1568-71

20. Reilly T, Walker G. Reasons for poor colonic preparation with inpatients. Gastroenterol Nurs 2004;115-7.

21. Arora A, Singh P. Colonoscopy in patients 80 years of age and older is safe, with high success rate and diagnostic yield. Gastrointest Endosc 2004;60:408-13.

22. Romagnuolo J, Enns R, Ponich T, Springer J, Armstrong D, Barkun A. Canadian credentialing guidelines for colonoscopy. Can J Gastroenterol 2008;22:17-22 


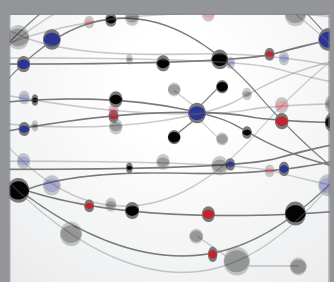

The Scientific World Journal
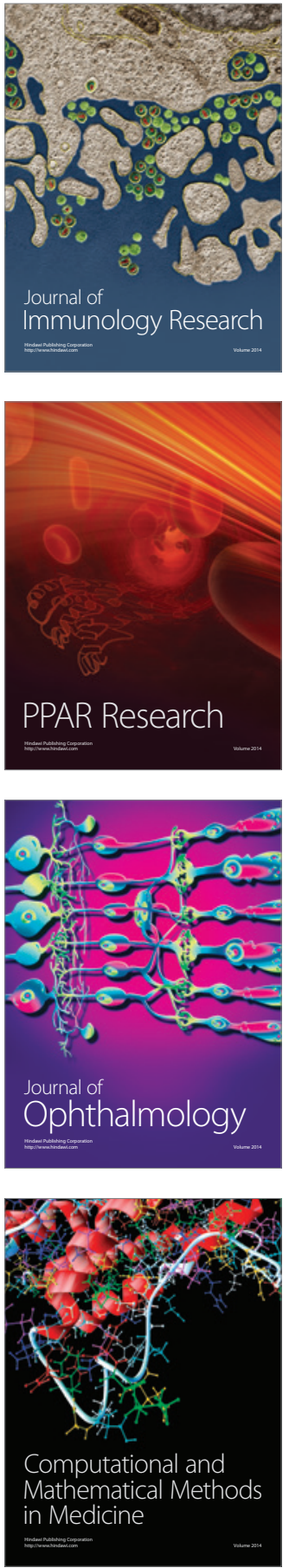

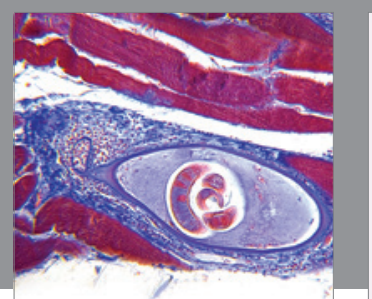

Gastroenterology Research and Practice

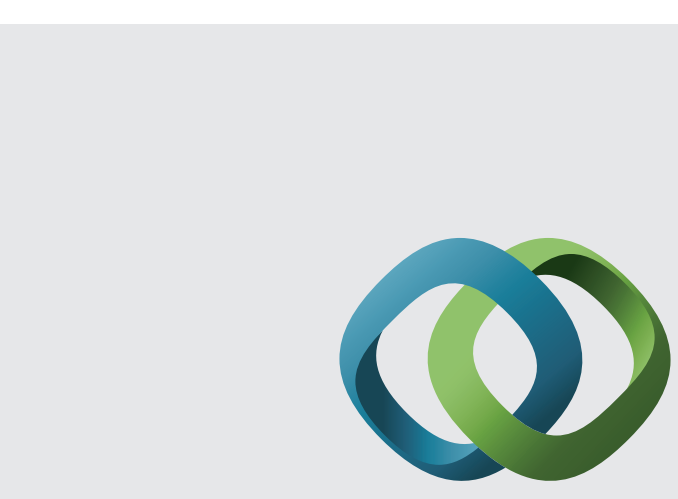

\section{Hindawi}

Submit your manuscripts at

http://www.hindawi.com
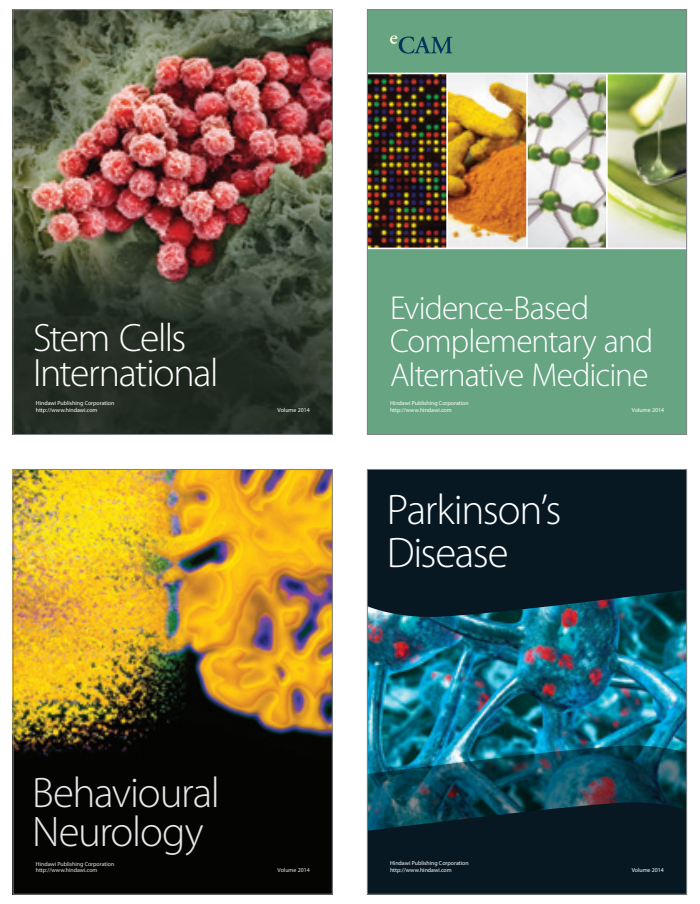
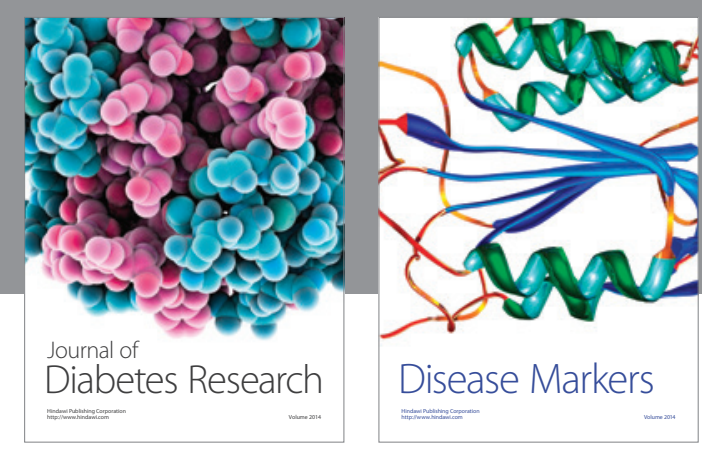

Disease Markers
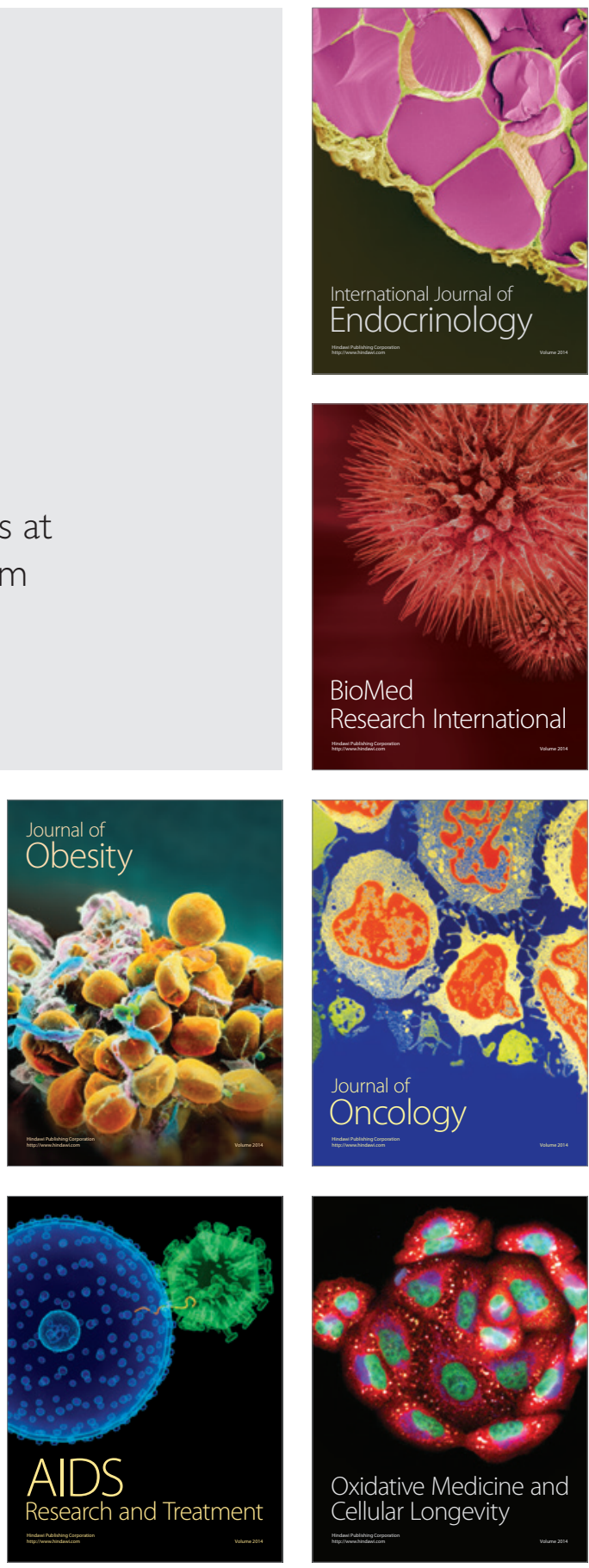